\title{
Wild Turkey (Meleagris gallopavo mexicana L.) Monitoring: Innovation in Sampling and Estimator of Population Density
}

\author{
Clemente-Sánchez, Fernando $^{1^{*}}$; Rosas-Rosas, Octavio César ${ }^{1}$; Tarango-Arámbula, Luis Antonio ${ }^{1}$ \\ ${ }^{1}$ Colegio de Postgraduados Campus San Luis Potosí. Iturbide 73, Salinas de Hidalgo, San Luis Potosí, México. \\ C. P. 78600. \\ *Corresponding author: clemente@colpos.mx
}

Citation: Clemente-Sánchez, Fernando1, Rosas-Rosas, Octavio César, TarangoArámbula, Luis Antonio. (2021). Wild Turkey (Meleagris gallopavo mexicana L.) Monitoring: Innovation in Sampling and Estimator of Population Density. Agro Productividad, 14(\#). https://doi. org/10.32854/agrop.v14i6.1982

Editor in Chief: Dr. Jorge Cadena Iñiguez

Estimated publication date: July 2021

This work is licensed under a Creative Commons Attribution-NonCommercial 4.0 International license

\begin{abstract}
Objective: To estimate the population of wild turkey (Meleagris gallopavo, mexicana) and its density in ecosystems of distribution.

Design/Methodology/Approach: A method based on random sampling with a population density estimator was designed. The design was based on the observation of wild turkeys that go to attraction sites (feedlots) of 2,500 $\mathrm{m}^{2}(50 \times 50 \mathrm{~m})$ counted in $12 \mathrm{~h}$ a day, three consecutive days. For all the random sites, the criterion of one site for every 300 ha of surface under study was used. The study was carried out on March 1, 2 and 3, 2019, in 3,000 ha of pine-oak forest, in Monte Escobedo, Zacatecas, Mexico. Observations were made from a fixed point $25 \mathrm{~m}$ away from each site, from 6:00 a.m. to 6:00 p.m. The attraction sites were located at a random distance within 10 systematically fixed transects in the study area.

Results: The results showed a population of 66 wild turkeys in 3,000 ha, with a density of 0.022 wild turkeys $\mathrm{ha}^{-1}$

Study Limitations/Implications: The application of the method was useful for monitoring wild turkey in the pine-oak forest, showing that it is a method that does not affect the population, which does not require long sampling times, is reliable, low-cost, and easy to carry out. The method is not reliable in ecosystems that do not allow the location of high visibility sites.

Findings/Conclusions: Considering the distribution of wild turkey in Mexico, the method is a new alternative applicable to population studies of wild turkey.
\end{abstract}

Keywords: Wild fauna; population; density; Meleagris gallopavo; sample size.

\section{INTRODUCTION}

For more than two decades, the "line transect" method has been used to estimate wild turkey population and abundance (Buckland et al., 2007) with its estimator for population density $(\mathrm{PD})=(\mathrm{n}) \mathrm{f}(0) / 2 \mathrm{~L}$. Despite being the most widely used (Anderson et al., 2001) and obtaining great benefits from its use (Ruette et al., 2003), its application for monitoring wild turkey populations is limited by the assumptions of the method, such as the impossibility of walking the transects in steep terrain, the movement of the wild turkeys along the transects that makes it impossible to count them, and the high probability of observing the same turkeys along other transects, which together yields unreliable results.

Various estimators have been proposed for monitoring wild turkey populations in North America. These estimators have been useful in defining population trends over time, and as an objective to evaluate the management activities carried out on the species and to assess the outcome of reintroductions in different ecosystems (Dahlheim et al., 2000; Rosenstock et al., 2002; Clemente-Sánchez and Tarango-Arámbula, 2007; Khan et al., 2016;). The study of wild turkey (Meleagris gallopavo mexicana) populations is sustained on the application of methods based on transect walks, scoring the number 
of wild turkeys observed on either side of the previously established transects in the study area. Other methods such as "capture and recapture" have also been used, with the problem of the impact produced during the marking process for later observation, the high number of turkeys needed for the estimation, and the loss of organisms due to trauma because of their capture, in addition to the time required to obtain the results of the estimation. In addition, these methods present complications in meeting the assumptions for their operation and application. Therefore, it is necessary to develop new estimators based on random sampling and statistical principles that allow predicting the size and density of the population. Only in this way would it be reliable to infer the number of wild turkeys to be managed for its harvest. Therefore, the objective of this study was to develop and apply a new method based on attraction sites to estimate the wild turkey population.

\section{MATERIALS AND METHODS}

In March 2019, in an area of 3000 ha $15 \mathrm{~km}$ north of the city of Monte Escobedo, in the mountain range of the state of Zacatecas, Mexico, sampling was carried out to determine the population density and size of wild turkey for harvesting purposes. The study included areas within and outside of Wildlife Management and Conservation Units (Unidades de Manejo para el Aprovechamiento y Conservación de la Vida Silvestre, UMA). In the study area, 10 linear transects of $2000 \mathrm{~m}$ separated $150 \mathrm{~m}$ from each other were systematically traced. Within each transect a random value between 0 and $2000 \mathrm{~m}$ was selected to locate the $50 \times 50 \mathrm{~m}$ attraction site. This way, the 10 sites or sampling plots were established with considerable visibility for counting wild turkeys. On the first, second and third day of March 2019, 10 observers were placed, one per sampling site, for which 10 hiding places for observation $(1 \times 1 \times 1 \mathrm{~m}) 30 \mathrm{~m}$ from each site were built. An observer was placed in each observation hiding lace to count wild turkeys during three consecutive days from 6:00 am to 6:00 pm. Observers entered the observation sites three days after the occurrence of turkeys was recorded at each site. The sites were baited with yellow corn and oats in bales 15 days before they began to enter the bait. A database was constructed with the following variables: site number, transect number, date, time of observation, number of wild turkeys observed, total females, total males, total juveniles, male/female ratio, and adult/juvenile ratio.

Method rationale. In order to be confident that a sample is representative of the population, it must be created randomly (Ghahramani, 2000; Prasanna, 2013). For finite populations (transects), random samples within transects are defined as a set of observations $x_{1}, x_{2}, \ldots x_{n}$ that constitute a random sample of size $n$, for a finite population of size $N$, provided that they are selected in such a way that each subset of $n$ elements among the $N$ elements of the population have the same probability of being chosen. Being a finite population (attraction sites), we can enumerate its constituent elements and then select a sample with the help of a table of random numbers, or through computer programs that generate such numbers (Murray and Stephens, 2005). There are various ways of selecting a random sample, taking care not to violate the 
hypotheses of statistical theory. Since we are interested in making inferences about population parameters, such as the mean $\mu$ and standard deviation $\sigma$ that we calculated from the sample observation, and since the selection of a random sample is governed by chance, the values obtained from these statistics will be as well (Rosenthal, 2000; Crespo, 2018). To apply the method of attraction sites for wild turkeys, the assumptions of the method are a) All the members of the population have an equal probability of being counted. b) No member of the population has the possibility of being counted more than once. c) The members of the population are spatially distributed in an aggregated manner. d) Sampling of the attraction sites is random. e) Mortality and recruitment during the period when the data are obtained are not significant.

Population and density. The method is designed for the sampling of wild turkeys that are spatially distributed in an aggregated manner at a certain time of the year (March to May) for reproduction in pine-oak, pine-aspen, pine, and other forest ecosystems, where sites with high visibility can be located.

The population is calculated from the total count of wild turkeys per site, adjusted for overlapping or overexposure of schedules at the sites, plus individuals that cannot be counted more than once due to their distance from the sites.

$$
P_{\text {total }}=\text { TTOS }+ \text { TTDS }
$$

(Equation 1)

Where; $P_{\text {total }}=$ total population. TTOS=Total number of turkeys in overlapping schedules. TTDS=Total number of turkeys at distant sites that cannot be counted more than once.

The density value for the sampling area is calculated in number of wild turkeys per hectare according to the following estimator:

$$
D P_{h a^{-1}}=P_{\text {total }} / T S A
$$

Where; $D P_{h a^{-1}}=$ population density in wild turkeys ha-1. TSA=Total study area.

Sample size. Based on the standard deviation and mean obtained from a set of values, we would expect a reliable estimate of the population to allow inferring about the actual size of the population. The method of attraction sites establishes the convenience of calculating the recommended sample size $(n)$ from the sampling. In this study, the application of this method was carried out for five years, using different sample sizes, and it was observed that the accuracy is not improved when more than 10 attraction sites with three replicates are used per 3000 ha in pine-oak forest vegetation. The repetitions correspond to the three days in which the present study was conducted.

Confidence limits. To estimate the confidence limit, a probabilistic analysis is not necessary, since the maximum limit is given by the total number of wild turkeys observed in all sites divided by capture effort (repetitions). This is based on the 
assumption that there will not be more than the observed total in the study area, given the effect that the attraction site has on the movements of the wild turkey once baited. The lower limit will be the result of the calculated total population $\left(P_{\text {total }}\right)$.

Statistical analysis. The population density and confidence limits were performed with the Microsoft Excel 2010 software.

\section{RESULTS AND DISCUSSION}

The data obtained at the end of March 1, 2 and 3, 2019, in the study area of 3000 ha in 10 attraction sites are presented in Table 1, where one can select the number of wild turkeys overlapping in their schedules and the schedule ranges that were observed.

Table 1. Record of turkeys observed in 2019 in three consecutive days (R), within 10 attraction sites in pine-oak forest of Monte Escobedo, Zacatecas.

\begin{tabular}{|c|c|c|c|c|c|c|c|}
\hline Site & Date & $\mathbf{R}$ & $\begin{array}{c}\text { Turkeys } \\
\text { observed }\end{array}$ & $\begin{array}{c}\text { Range time of } \\
\text { observation }\end{array}$ & Females & Males & Juveniles \\
\hline 1 & $\begin{array}{l}01 / 03 / 19 \\
02 / 03 / 19 \\
03 / 03 / 19 \\
\end{array}$ & $\begin{array}{l}1 \\
2 \\
3 \\
\end{array}$ & $\begin{array}{c}15,12 \\
21 \\
8,11 \\
\end{array}$ & $\begin{array}{c}9-10,10-11 \\
9-10 \\
9-10,14-15\end{array}$ & $\begin{array}{c}10,9 \\
15 \\
11,8 \\
\end{array}$ & $\begin{array}{c}5,3 \\
0 \\
0,0 \\
\end{array}$ & $\begin{array}{c}0,0 \\
6 \\
0,0 \\
\end{array}$ \\
\hline 2 & $\begin{array}{l}01 / 03 / 19 \\
02 / 03 / 19 \\
03 / 03 / 19\end{array}$ & $\begin{array}{l}1 \\
2 \\
3\end{array}$ & $\begin{array}{c}8,5 \\
5,7 \\
4\end{array}$ & $\begin{array}{c}9-10,11-12 \\
9-10,10-11 \\
10-11\end{array}$ & $\begin{array}{c}8,0 \\
5,5 \\
4\end{array}$ & $\begin{array}{c}0,5 \\
0,2 \\
0\end{array}$ & $\begin{array}{c}0,0 \\
0,0 \\
0\end{array}$ \\
\hline 3 & $\begin{array}{l}01 / 03 / 19 \\
02 / 03 / 19 \\
03 / 03 / 19\end{array}$ & $\begin{array}{l}1 \\
2 \\
3 \\
\end{array}$ & $\begin{array}{c}2,15 \\
3,12 \\
9 \\
\end{array}$ & $\begin{array}{c}13-14,15-16 \\
13-14,15-16 \\
17-18\end{array}$ & $\begin{array}{c}2,9 \\
3,8 \\
7 \\
\end{array}$ & $\begin{array}{c}0,6 \\
0,0 \\
0 \\
\end{array}$ & $\begin{array}{c}0,0 \\
0,4 \\
2 \\
\end{array}$ \\
\hline 4 & $\begin{array}{l}01 / 03 / 19 \\
02 / 03 / 19 \\
03 / 03 / 19\end{array}$ & $\begin{array}{l}1 \\
2 \\
3 \\
\end{array}$ & $\begin{array}{c}9 \\
11 \\
9 \\
\end{array}$ & $\begin{array}{l}17-18 \\
17-18 \\
10-11 \\
\end{array}$ & $\begin{array}{l}4 \\
6 \\
0 \\
\end{array}$ & $\begin{array}{l}5 \\
5 \\
0\end{array}$ & $\begin{array}{l}0 \\
0 \\
9 \\
\end{array}$ \\
\hline 5 & $\begin{array}{l}01 / 03 / 19 \\
02 / 03 / 19 \\
03 / 03 / 19\end{array}$ & $\begin{array}{l}1 \\
2 \\
3 \\
\end{array}$ & $\begin{array}{l}7 \\
0 \\
0 \\
\end{array}$ & $17-18$ & & & \\
\hline 6 & $\begin{array}{l}01 / 03 / 19 \\
02 / 03 / 19 \\
03 / 03 / 19 \\
\end{array}$ & $\begin{array}{l}1 \\
2 \\
3 \\
\end{array}$ & $\begin{array}{l}5 \\
9 \\
2 \\
\end{array}$ & $\begin{array}{c}8-9 \\
9-10 \\
9-10 \\
\end{array}$ & $\begin{array}{l}0 \\
7 \\
2 \\
\end{array}$ & $\begin{array}{l}0 \\
2 \\
0 \\
\end{array}$ & $\begin{array}{l}5 \\
0 \\
0 \\
\end{array}$ \\
\hline 7 & $\begin{array}{l}01 / 03 / 19 \\
02 / 03 / 19 \\
03 / 03 / 19\end{array}$ & $\begin{array}{l}1 \\
2 \\
3 \\
\end{array}$ & $\begin{array}{l}0 \\
3 \\
0 \\
\end{array}$ & $10-11$ & 3 & 0 & 0 \\
\hline 8 & $\begin{array}{l}01 / 03 / 19 \\
02 / 03 / 19 \\
03 / 03 / 19\end{array}$ & $\begin{array}{l}1 \\
2 \\
3 \\
\end{array}$ & $\begin{array}{l}18 \\
18 \\
10 \\
\end{array}$ & $\begin{array}{l}10-11 \\
10-11 \\
14-15 \\
\end{array}$ & $\begin{array}{c}12 \\
12 \\
8 \\
\end{array}$ & $\begin{array}{l}6 \\
6 \\
2 \\
\end{array}$ & $\begin{array}{l}0 \\
0 \\
0\end{array}$ \\
\hline 9 & $\begin{array}{l}01 / 03 / 19 \\
02 / 03 / 19 \\
03 / 03 / 19\end{array}$ & $\begin{array}{l}1 \\
2 \\
3 \\
\end{array}$ & $\begin{array}{l}7 \\
8 \\
4 \\
\end{array}$ & $\begin{array}{l}10-11 \\
14-15 \\
14-15 \\
\end{array}$ & $\begin{array}{l}4 \\
5 \\
3 \\
\end{array}$ & $\begin{array}{l}3 \\
3 \\
0 \\
\end{array}$ & $\begin{array}{l}0 \\
0 \\
1 \\
\end{array}$ \\
\hline 10 & $\begin{array}{l}01 / 03 / 19 \\
02 / 03 / 19 \\
03 / 03 / 19\end{array}$ & $\begin{array}{l}1 \\
2 \\
3\end{array}$ & $\begin{array}{c}3,9 \\
5 \\
0 \\
\end{array}$ & $\begin{array}{c}16-17,10-11 \\
16-17\end{array}$ & $\begin{array}{c}0,4 \\
0\end{array}$ & $\begin{array}{c}0,5 \\
0\end{array}$ & $\begin{array}{c}3,0 \\
5\end{array}$ \\
\hline \multicolumn{3}{|r|}{ Total } & 274 & & 179 & 60 & 35 \\
\hline
\end{tabular}

$\mathrm{R}=$ replica 
With the purpose of observing the total number of wild turkeys by time overlap and the total number of turkeys considered by the distance of the sites, Table 2 shows that there are two overlaps in the time ranges of 9-10 $\mathrm{h}$ and 10-11 $\mathrm{h}$.

Table 2. Overlap of turkeys observed in time ranges in three days of sampling within 10 attraction sites in a pine-oak forest in Monte Escobedo, Zacatecas.

\begin{tabular}{c|c|c|c|c|c|c|c|c|c|c}
\hline \multirow{2}{*}{ Site } & \multicolumn{7}{c}{ Time ranges (h) with the number of turkeys observed } \\
\cline { 2 - 12 } & $\mathbf{9 - 1 0}$ & $\mathbf{1 0 - 1 1}$ & $\mathbf{1 1 - 1 2}$ & $\mathbf{1 2 - 1 3}$ & $\mathbf{1 3 - 1 4}$ & $\mathbf{1 4 - 1 5}$ & $\mathbf{1 5 - 1 6}$ & $\mathbf{1 6 - 1 7}$ & $\mathbf{1 7 - 1 8}$ & Total \\
\hline 1 & $15,11,21$ & 12 & & & & 8 & & & & 67 \\
\hline 2 & 8,5 & 7,4 & 5 & & & & & & & 29 \\
\hline 3 & & & & & 2,3 & & 15,12 & & 9 & 41 \\
\hline 4 & & 9 & & & & & & & 9,11 & 29 \\
\hline 5 & & & & & & & & & 7 & 7 \\
\hline 6 & $5,9,2$ & & & & & & & & & 16 \\
\hline 7 & & 3 & & & & & & & & 3 \\
\hline 8 & & 18,18 & & & & 10 & & & & 46 \\
\hline 9 & & & & & & $7,8,4$ & & & & 19 \\
\hline 10 & & 9 & & & & & & 3,5 & & 17 \\
\hline Total & 76 & 80 & 5 & & 5 & 37 & 27 & 8 & 36 & 274 \\
\hline
\end{tabular}

Overlapping schedules gave a total of 150 wild turkeys $(76+80)$ plus 44 wild turkeys $(8+36)$ from sites that could not be visited by other turkeys because of their distance and schedule range. Having obtained the total number of wild turkeys under the previous criteria, we have the total observed population, and now it must be adjusted by the capture effort, which is three days, giving a total of 200/3=66 wild turkeys. Now, the population density is calculated with Equation 2.

$$
D P_{h a^{-1}}=P_{\text {total }} / T S A
$$

Replacing;

$$
D P_{h a^{-1}}=66 / 3,000=0.022
$$

It can be said that the population in the study area is at least 66 wild turkeys and at most 150 wild turkeys with a density of at least 0.022 wild turkeys $\mathrm{ha}^{-1}$, and at most 0.05 wild turkeys ha-1.

The female:male ratio was 2.98:1 (179 females/60 males) and the adult:juvenile ratio was 6.82:1 (239/35).

Our results agree with those reported for several states in the United States of America, where for pine-oak ecosystems in New Mexico, USA, they report densities of 3 wild turkeys $\mathrm{mi}^{-1}$ equivalent to 0.011 wild turkeys $\mathrm{ha}^{-1}$; in Texas in the same habitat 5 wild turkeys $\mathrm{mi}^{-1}$ equivalent to 0.019 wild turkeys ha ${ }^{-1}$ (McLaughlin, 2014). However, our results do not agree with those reported in Mexico in the sierra of La Michiía, Durango (Garza and Servin, 1993) with pine-oak vegetation where they report densities 
ranging from 1.6 wild turkeys $\mathrm{km}^{2}$ (0.0000016 wild turkeys ha-1) to 6.0 wild turkeys $\mathrm{km}^{2}\left(0.000006\right.$ wild turkeys ha $\left.{ }^{-1}\right)$, results that would be expected to be like those of the Monte Escobedo Mountain range. Perhaps because of the method used in La Michiía, the results are quite underestimated, since they are not based on observed animals, but rather signs of their presence. These methods frequently lead to erroneous estimates (Clemente-Sánchez and Tarango-Arámbula, 2007). In another study, Erxleben et al. (2010), with Rio Grande wild turkeys in North, Central and South Texas conducted a study to test the distribution of wild turkeys using radio telemetry. They observed great variation in the distribution of the populations, which resulted in the assumptions of the line transect method not being met, since the distribution of the wild turkey was not homogeneous. In this study, the transect sample was not random, so the authors recommend that before applying any population estimation method, a prior study of its distribution should be made.

\section{CONCLUSION}

The monitoring of wild turkey populations is based on the gregarious habits of the species, the type of ecosystem, their movements over time, as well as their interaction with the presence of humans and the selection or use of habitat during the day. The population estimators currently used lack reliability due to the impossibility of meeting the assumptions of their application.

The population of wild turkey in the study area of Monte Escobedo, Zacatecas, showed good abundance, with characteristics of a stable population from the number of adults and their relationship with juveniles.

The method of attraction sites is a new alternative to obtain reliable estimates of characteristic parameters of the population, such as the density of wild turkeys per surface unit and the size of the population.

\section{ACKNOWLEDGEMENTS}

We thank the technical manager of UMA Agua Nueva, Ricardo Montañez Lugo, for his participation in the sampling and for lodging facilities to carry out this study. We are grateful to the Dirección General de Vida Silvestre (SEMARNAT) for their interest in the development of the method; and to Colegio de Postgraduados Campus San Luis Potosí, for the time and economic support in the development and application of the method.

\section{REFERENCES}

Anderson, D. R., K. P. Burnham, B. C. Lubow, L. Thomas, P. S. Corn, P.A. Medica, and R. W. Marlow. 2001. Field trials of line transect methods applied to estimation of desert tortoise abundance. Journal of Wildlife Management 65:583-597.

Buckland, S. T., Anderson, D. R., Burnham, K. P., Laake, J. L., Brochers, D. L., y Thomas, L. 2007. Advanced distance sampling. Oxford University Press, New York.

Clemente-Sánchez, F., y Tarango-Arámbula, L. A. 2007. Métodos de estimación de Poblaciones de Fauna Silvestre. Principios y Prácticas, Capítulo 5. In OliveraLópez, J. I, Jaramillo-Jaimes, M. T., Molina-Hernández, M, Téllez-Alcántara, N. P. Editores. Reproducción y Manejo de Fauna Silvestre 3. Universidad Autónoma Metropolitana, Universidad Veracruzana. 
Crespo, A. F. 2018. Métodos Estadísticos. Ejercicios Resueltos y Teoría. Editorial UIVERSITAT Politécnica de Valencia. ISBN: 9788490486689.

Dahlheim, M., A. York, R. Towell, J. Waite, y J. Breiwick. 2000. Harbor porpoise (Phocoena phocoena) abundance in Alaska: Bristol Bay to southeast Alaska, 1991-1993. Marine Mammal Science 16:pp.28-45.

Erxleben, D. L., Butler, M. J., Ballard, W. B., Wallace, M. C., Peterson, M.J., Silvy, N. J., Kuvlesky, W.P. Jr., Hewitt, D. G., DeMaso, S. J., Hardin, J. B., Dominguez-Brazil, M. K. 2010. Wild Turkey (Meleagris gallopavo) association to roads: implications for distance sampling. European Journal Wildlife Research (2011) 57:pp.57-65.

Garza, A. y Servin, J. 1993. Estimación de la población y utilización del hábitat del cócono silvestre (Meleagris gallopavo, aves: phasianidae) en Durango, México. Ecología Austral: 3: pp.15-23.

Ghahramani, S. (2000). Fundamentals of Probability. Upper Saddle River, New Jersey: Prentic eHall.

Khan, B., Ablimit, A., Khan, G., Jasra, A., Ali, H., Ali, R., Ahmad, E., y Ismail, M. 2016. Abundance, distribution and conservation status of Siberian Ibex, Marco Polo and Blue sheep in Karakoram-Pamir mountain area. Journal of King Saud University Science 28:pp.216-225.

McLaughlin, R. 2014. Map: Turkey density in the United States. Vox november. https://www.vox.com/2014/11/27/7259155/turkeydensity

Murray, S. y Stephens, L. 2005. Theory and problems of statistics. 4a Ed. Mc Graw-Hill.

Prasanna, S. 2013. Probability and Mathematical Statistics. Department of Mathematics University of Louisville, Louisville, KY 40292 USA

Rosenthal, J.S. 2000. A First Look at Rigorous Probability Theory. Singapore: World Scientific.

Rosenstock, S. S., D. R. Anderson, K. M. Giesen, T. Leukering, and M. F. Carter. 2002. Landbird counting techniques: current practices and an alternative. Auk 199:pp.46-53.

Ruette, S., P. Stahl, and M. Albaret. 2003. Applying distance-sampling methods to spotlight counts of red foxes. Journal of Applied Ecology 40: pp.32-43. 